\title{
Discriminating spontaneous locomotor play of dairy calves using accelerometers
}

\author{
V. Größbacher, ${ }^{1 *} \odot$ K. Bučková, ${ }^{2,3}$ A. B. Lawrence, ${ }^{4}$ M. Špinka, ${ }^{2,3}$ ๑ and C. Winckler ${ }^{1} \oplus$ \\ ${ }^{1}$ Department of Sustainable Agricultural Systems, University of Natural Resources and Life Sciences, 1180 Vienna, Austria \\ 2Department of Ethology and Companion Animal Science, Czech University of Life Sciences, 16500 Prague, Czech Republic \\ ${ }^{3}$ Department of Ethology, Institute of Animal Science, 10400 Praha Uhříněves, Czech Republic \\ ${ }^{4}$ Animal and Veterinary Sciences Research Group, SRUC (Scotland's Rural College), Edinburgh, EH9 3JG, United Kingdom
}

\begin{abstract}
Play behavior is a promising welfare indicator in dairy calves because it decreases in negative situations such as pain or hunger and increases in positive contexts such as in appropriate social environments. Directly measuring play is time consuming because it is performed in irregular bouts and can be inconsistent over days. To facilitate automatic recording of play, previous studies fitted triaxial accelerometers to the hind legs of calves and measured the velocity of movements in large arenas; high correlations were reported between vertical axis peak duration and the duration of locomotor play. The current study aimed to validate accelerometers for recording spontaneous locomotor play in calves' home pens over longer periods. Data were collected from 48 Holstein Friesian calves, housed in groups of 3 in pens of $10 \mathrm{~m}^{2}$, at either 4 or $8 \mathrm{wk}$ of age. Acceleration at the vertical axis of the hind leg was recorded at a rate of 1 $\mathrm{Hz}$. One active time period for each calf was randomly selected (mean duration \pm standard deviation $=34 \pm 9$ min). From video of the corresponding time period, the frequency of locomotor play events, consisting of run, turn, and buck/buck-kick, was recorded using behavior sampling. Combined counts of play events were highly correlated (Pearson $r=0.91$ ) with counts of acceleration peaks. However, for calves with higher levels of locomotor play, this method underestimated the extent of play. Alternatively, run, turn, and buck events obtained from video were transformed by creating intervals of 10 $\mathrm{s}$ and then classifying each 10-s interval as comprising events of play ("play") or not comprising events of play ("no play"). The corresponding accelerometer data for all 10-s periods, equaling 10 consecutive readings each, were classified into play or no play by using quadratic
\end{abstract}

Received May 22, 2019.

Accepted October 1, 2019.

*Corresponding author: verena.groessbacher@boku.ac.at discriminant analysis; $79 \%$ of periods with locomotor play were correctly classified. Counts of observed play intervals correlated with the counts of play periods from accelerometers $(r=0.87)$, but the discriminant analysis consistently overestimated play. In conclusion, accelerometer measurements at $1 \mathrm{~Hz}$ (in 1-s intervals) and at the vertical axis cannot be used alone to exactly quantify absolute levels of locomotor play in the home pen. However, counts of peak accelerations can provide a rough estimate of inter-individual differences in play events, and discriminant analysis can be used as a proxy for one-zero sampling of inter-individual differences in locomotor play.

Key words: automated measuring, acceleration, behavior classification, dairy calf

\section{INTRODUCTION}

In the past decade, accelerometers have found increasing application in farm animal research. The use of accelerometers facilitates data collection because automatic recording can circumvent time- and resource-intensive behavior observations. In calves, accelerometers have been primarily used to record general activities. For example, lying, standing, or locomotion of dairy calves has been recorded using accelerometers to detect early behavioral signs of respiratory diseases (Swartz et al., 2017) and of neonatal diarrhea (Sutherland et al., 2018b). Moreover, acceleration measurements have been used to quantify lying and standing when studying effects of social housing on weaning (Overvest et al., 2018) and determining effects of different disbudding methods on lying behavior (Sutherland et al., 2018a). Although the accuracy of recording general activities from accelerometers is high, the validation of recording specific behaviors such as feeding and ruminating is still in progress (e.g., Roland et al., 2018).

In calves, play behavior is a promising indicator to assess both compromised welfare-for example, reduced play due to pain after disbudding (Mintline 
et al., 2013) or hunger after weaning off milk (Krachun et al., 2010; Miguel-Pacheco et al., 2015) —and enhanced welfare, such as increased play when housed in groups (Valníčková et al., 2015). However, calves perform spontaneous play for only a few minutes per day (Jensen et al., 2015) at irregular intervals (Fraser and Duncan, 1998). Thus, quantification of play from observation is usually accomplished either through continuous recording of durations or events (e.g., Jensen et al., 2015; Miguel-Pacheco et al., 2015) or through one-zero sampling of the presence of play in certain sample intervals (e.g., Valníčková et al., 2015). These challenges associated with measuring play behavior have raised interest in automatic recording techniques. In previous studies, accelerometers were used to automatically record locomotor play of calves; however, the recordings were conducted in large arenas and for a short time only. Rushen and de Passillé (2012) found Spearman correlations of up to 0.88 between the duration of running and the sum of total acceleration in all 3 axes, and Luu et al. (2013) found Pearson correlations of up to 0.98 between the duration of locomotor play (running plus jumping/kicking) and the sum of the percent of peaks ( $3 \mathrm{~g}$ or higher) of all axes. In both studies, acceleration was recorded at a high rate of 33 $\mathrm{Hz}$ and in all 3 axes, limiting the recording duration to $10 \mathrm{~min}$ due to the memory capacity of the accelerometers (Hobo Pendant G Acceleration Data Logger, Onset Computer Corp., Pocasset, MA). With the intention of assessing a longer recording duration, Luu et al. (2013) simulated a sampling frequency of $1 \mathrm{~Hz}$ by taking every 33rd acceleration reading on one axis only and found a Pearson correlation of 0.92 between the percent of peaks on the vertical axis and the duration of locomotor play. To test the practical application of measuring spontaneous locomotor play over the duration of many hours, in the current study, we aimed to validate the use of accelerometers to measure play behavior in the home pens of calves at low recording rates. Specifically, our objectives were to use recordings at $1 \mathrm{~Hz}$ on the vertical axis (1) to test whether counts of peak accelerations can accurately estimate events of locomotor play, and (2) to determine whether classifying periods of acceleration readings into "play" and "no play" could reliably measure play behavior recorded by one-zero sampling from video.

\section{MATERIALS AND METHODS}

All data were collected at the Netluky Research Station at the Institute of Animal Science (Prague, Czech Republic) between August 2016 and April 2017. The study was approved by the Institutional Animal Care and Use Committee of the Institute of Animal Sci- ence in Prague and the Czech Central Committee for Protection of Animals, Ministry of Agriculture (permit number 27356/2016-MZE-17214).

\section{Animals and Housing}

The 48 Holstein Friesian-calves (20 female, 28 male) reported on here were a subset of a larger study using 72 calves. Among the 72 calves, 2 focal calves per group were randomly selected, with observations of one calf taking place at $4 \mathrm{wk}$ and the other at $8 \mathrm{wk}$ of age. Calves weighed $57.5 \pm 5.7 \mathrm{~kg}$ (mean $\pm \mathrm{SD}$ ) at $4 \mathrm{wk}$ and $88.3 \pm 12.4 \mathrm{~kg}$ at $8 \mathrm{wk}$. Groups were housed in an uninsulated barn with windshields in 24 groups of 3 . Pens were $10.1 \mathrm{~m}^{2}$ with a straw-bedded lying area of 4.2 $\times 1.4 \mathrm{~m}$ and a concrete activity and feeding area of 3.5 $\times 1.2 \mathrm{~m}$. Calves entered group housing at an average age of $13.3 \pm 3.1 \mathrm{~d}$ (mean $\pm \mathrm{SD}$ ) with groups entering the experiment consecutively. Calf allocation to groups was balanced for sex, age, and weight. For the purpose of another experiment, calves were fed either $6 \mathrm{~L} / \mathrm{d}$ of milk throughout the experiment or received $9 \mathrm{~L} / \mathrm{d}$ at wk 4 with the provision continuously increasing to 12 L in wk 6 . All calves received 3 milk meals per day in teat buckets, and all calves received $3 \mathrm{~L}$ of milk in the morning. Calves with the low milk allowance received $1.5 \mathrm{~L}$ of milk per meal at midday and in the evening. Calves with the high milk allowance received $3 \mathrm{~L}$ at midday and in the evening, which continually increased to $4.5 \mathrm{~L}$ of milk per meal. Calves had ad libitum access to water, concentrates, and hay offered in buckets.

\section{Acceleration Measurements}

Accelerometers (Hobo Pendant G Acceleration Data Logger, Onset Computer Corp.; product specifications are described in detail in Luu et al., 2013) were fitted to the rear side of both hind legs of calves using elastic cohesive bandages. Accelerometers were attached vertically to the leg such that the $\mathrm{x}$-axis was perpendicular to the ground. The accelerometers were set to measure readings on the vertical axis at a rate of $1 \mathrm{~Hz}$ (1 sample/s), allowing recording of acceleration every second for $18.1 \mathrm{~h}$. Acceleration was recorded from 0500 until $2304 \mathrm{~h}$ on 2 consecutive days per testing week, with the accelerometer on the right leg recording $\mathrm{d} 1$ and that on the left leg recording $\mathrm{d} 2$. Calves wore accelerometers for approximately $66 \mathrm{~h}$ per testing week (from the evening before until the morning after the testing days). Programming of accelerometers was performed using an optical infrared base station with USB interface and the Hoboware Pro Software (version 3.7.8; Onset Computer Corp.) with the starting time set in advance. 
Table 1. Ethogram of locomotor play derived from Jensen et al. (1998) and Jensen and Kyhn (2000)

\begin{tabular}{ll}
\hline Type of locomotor play & Description \\
\hline Running & $\begin{array}{l}\text { Rapid gait with phase of suspension in the air. Minimum of } 2 \text { consecutive suspension movements in a forward } \\
\text { direction. Running is counted as a new event after 1-s break. }\end{array}$ \\
Turning & $\begin{array}{l}\text { The } 2 \text { forelegs are lifted from the ground and stretched forward, as the forepart of the body is elevated } \\
\text { and turned to one side. Movement upward and sideward for a minimum of } 90^{\circ} .\end{array}$ \\
running bouts.
\end{tabular}

\section{Behavior Observation}

Behavior of calves was video recorded for $48 \mathrm{~h}$ per testing week using one camera per pen (VCC-HD2300P, Sanyo, Osaka City, Japan; FW2220R-Z, Dahua Technology Co., Hangzhou, China; HDC-SD99, Panasonic, Osaka City, Japan) and infrared radiators (RM50AI-50, Raytec, Ashington, UK; LIR-T80 and LIR-T60, IR LAB Surveillance Tech, Shenzhen, China). Based on the graphic display of downloaded acceleration values using the plot function of the Hoboware Pro Software, lying and active phases could be clearly distinguished; therefore, one activity bout of approximately $30 \mathrm{~min}$ was selected for each calf. Activity bouts were selected in a time span between 0500 and $2000 \mathrm{~h}$, when accelerometer recordings were available, and video recordings allowed easy distinction of behaviors due to daylight hours. The week and day of the selected activity bout was randomized for each focal calf. Selection of activity bouts was balanced across different times of the day, and the start time of selected bouts ranged from 0604 to $1923 \mathrm{~h}$. The duration of selected activity bouts was $34.3 \pm 9.2$ min (mean $\pm \mathrm{SD}$ ). For individual recognition, calves were marked across their backs and sides with animal marking sticks. Behaviors categorized as locomotor play are described in Table 1 . The criterion interval for halts between running events was set to 1 $\mathrm{s}$ based on visual assessment of a log survivorship plot. Events of locomotor play behavior were continuously recorded by one person using the Mangold Interact video analysis software (version 16.1.5.8; Mangold International GmbH, Arnstorf, Germany). Intra-observer reliability was measured from 3 randomly selected activity bouts of $41.7 \pm 8.0 \mathrm{~min}$ each (mean $\pm \mathrm{SD}$ ) assessed 2 times. Wexler's ratio was calculated from the number of agreements (i.e., the number of locomotor play events that were correctly scored within $1 \mathrm{~s}$ in both recording sessions $\times 2$ ) divided by the number of possible agreements (i.e., the total number of locomotor play events scored in both sessions, as used in Wathan et al., 2015). Wexler's ratio was assessed for each activ- ity bout individually, with an average agreement ratio of 0.84. Continuous recording was transformed into one-zero sampling by creating sample intervals of $10 \mathrm{~s}$ and classifying them according to presence or absence of locomotor play events within the interval.

\section{Data Analysis}

All statistical analyses were performed in SAS 9.4 (SAS Institute, 2012). We analyzed the acceleration data according to 2 methodologies, the peak acceleration method and the classifier method.

Peak Acceleration Method. We used Pearson correlations to assess the strength of association between counts of peak measurements of acceleration (peak method) and counts of observed locomotor play events. Counts of peak accelerations were calculated for different upper and lower thresholds of acceleration values in steps of $0.1 \mathrm{~g}$ (e.g., counts of values $\geq 3.2 \mathrm{~g}, 3.1 \mathrm{~g}, 3.0$ $g, \ldots$ and $\leq-3.2 \mathrm{~g},-3.1 \mathrm{~g},-3.0 \mathrm{~g})$. Pearson correlations of all 1,056 combinations (33 thresholds of $\geq 0 \mathrm{~g}$ $\times 32$ thresholds of $<0 \mathrm{~g}$ ) of counts of peaks, applying different upper and lower thresholds, with counts of locomotor play were calculated. The best combination of threshold values of acceleration to predict locomotor play was identified as counts of peaks $\geq+1.6 \mathrm{~g}$ and $\leq$ $-3.0 \mathrm{~g}$. Although the distribution of data was rightskewed and did not visually conform to the assumption of normality for parametric measures of association, the data distribution was unimodal. Three outliers were visually detected using a Cook's distance plot, although no outlier with leverage was visually identified in the outlier and leverage diagnostics (leverage and studentized residuals).

Classifier Method. We used quadratic discriminant analysis to predict a categorical response (Kuhlenkasper and Handl, 2017); that is, the occurrence of locomotor play in each period (10-s fragment of observations) based on classifiers (predictor variables describing acceleration values in each period; James et al., 2015). Because discriminant analysis requires 2 sets of data, 
Table 2. Descriptions and equations of the classifiers included in the final discriminant function are shown for the testing data set identified as play or no play from video

\begin{tabular}{|c|c|c|c|}
\hline Classifier & Equation & No play & Play \\
\hline Mean of 2 highest $(\max )$ acceleration measurements $(x)$ & $\underline{\max (x)+\max 2(x)}$ & $-0.89 \pm 0.21$ & $0.04 \pm 0.99$ \\
\hline Mean of 2 lowest (min) acceleration measurements $(x)$ & $\frac{\min (x)+\min 2(x)}{2}$ & $-1.06 \pm 0.20$ & $-1.85 \pm 0.70$ \\
\hline Variance $(\mu=$ mean $)$ & $\frac{\sum(x-\mu)^{2}}{10}$ & $0.03 \pm 0.10$ & $0.74 \pm 0.80$ \\
\hline Maximum of absolute value of change $(\Delta)$ in acceleration measurements $(x)$ & $\max (|\Delta x|)$ & $0.26 \pm 0.48$ & $2.41 \pm 1.45$ \\
\hline Mean change $(\Delta)$ in acceleration measurements $(x)$ & $\frac{1}{10} \sum \Delta x_{i}$ & $-0.00 \pm 0.03$ & $-0.01 \pm 0.12$ \\
\hline Total sum of absolute values of change $(\Delta)$ in acceleration measurements $(x)$ & $\sum\left|\Delta x_{i}\right|$ & $0.66 \pm 1.15$ & $6.96 \pm 4.78$ \\
\hline
\end{tabular}

${ }^{1}$ No play $=$ period with absence of locomotor play; Play = period with presence of locomotor play. Values shown are means \pm standard deviation.

1 to train the discriminant function and 1 to test its predictions, we divided the recorded activity bouts in half. Therefore, the accelerometer data were combined into 10-s periods, resulting in 10 measurements per period. Subsequently, periods were alternately allocated to a training data set or a testing data set (testing data set: $\mathrm{n}=48$, mean number of periods $\pm \mathrm{SD}=$ $102.3 \pm 26.9$ ). The presence (play) or absence (no play) of locomotor play in each period was identified from video observation and used as the gold standard. For each period, the following metrics were calculated as classifiers derived from the original value or change in values $\left(=x_{i}-x_{i-1}\right)$; for example, minimum, maximum, mean, median, quartiles, variance, total sum; a full list is provided in Supplemental Table S1 (https://doi.org/ 10.3168/jds.2019-17005). Relevant classifiers were then visually preselected from boxplots of "play" and "no play" from the training data set when the interquartile range of "no play" was low with little to no overlap with "play" and when outliers were not widely dispersed. A quadratic discriminant function was then developed with classification probabilities based on the proportional occurrences of how often "play" and "no play" were scored in the training data set; that is, $97 \%$ of periods displaying no play and $3 \%$ of periods displaying play. With the testing data set, the predictive abilities of the discriminant function were assessed. Discriminant functions with different combinations of classifiers were tested and the combination of classifiers with the highest sensitivity and specificity was selected. The relevant classifiers included in the final discriminant function are displayed in Table 2. Discriminant analysis assumes a Gaussian distribution from observations of each class (James et al., 2015). The present data of the values of classifiers could not be assumed to be normally distributed nor could data be transformed to fit the underlying assumptions of normality. We were able to circumvent this issue by dividing the data set into 2 halves, a training data set and a testing data set. The performance of the discriminant function was not contingent on the data distribution and could be independently verified.

Comparison of Methods. To directly contrast the outcome of the 2 methods based on the same set of data, we calculated the peak acceleration method (PEAK) and the classifier method (CLASS) with the testing data set only $(\mathrm{n}=48$; mean duration $\pm \mathrm{SD}$ $=17.1 \pm 4.6 \mathrm{~min})$. To assess the strength of association between measures of acceleration and the observed locomotor play, we calculated a Pearson correlation of counts of peaks resulting from the peak acceleration method and counts of observed locomotor play events. Likewise, we calculated a Pearson correlation of counts of play periods resulting from the classifier method with counts of observed locomotor play intervals from one-zero sampling. To assess the magnitude of disagreement and facilitate the detection of trends, we produced Bland-Altman plots that depict the average of the acceleration measure and the observation on the $\mathrm{x}$-axis and the difference between the acceleration measure and the observation on the y-axis (Altman and Bland, 1983). Bland-Altman plots were produced for both methods of analysis and compared visually.

\section{RESULTS}

When assessing play by continuous recording of frequencies, calves performed 5.3 events of locomotor play per 30 -min observation period $(\mathrm{SD}=7.3$; range $=0-27)$. The Pearson correlation of counts of peaks of $\geq+3.0 \mathrm{~g}$ and $\leq-3.0 \mathrm{~g}$ with the corresponding accelerometer data, as described by Luu et al. (2013), 


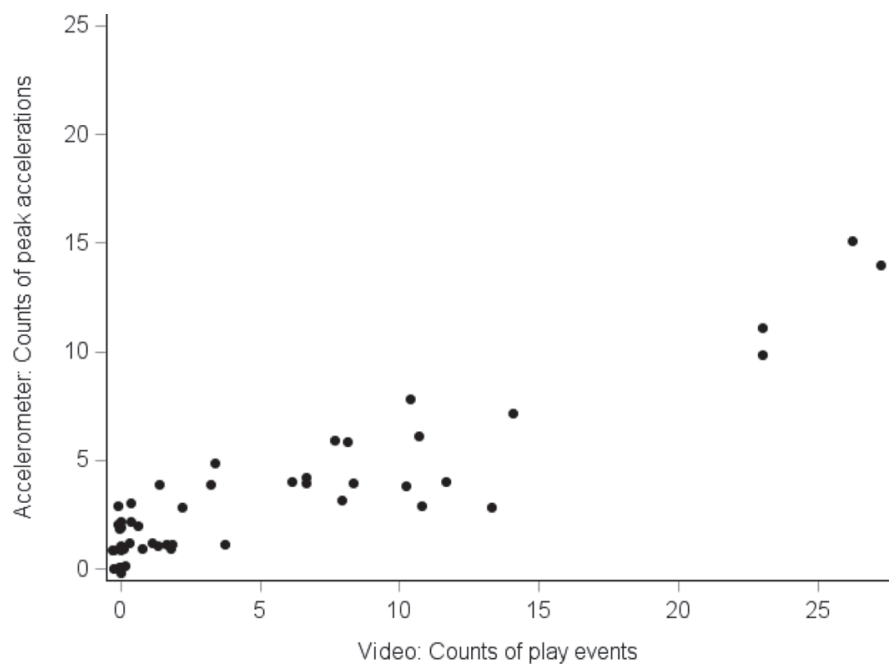

Figure 1. Relationship between counts of peak accelerations $(\geq 1.6$ $g$ and $\leq 3.0 g$; peak acceleration method) and counts of locomotor play events observed from video ( $\mathrm{n}=48$ calves). Jitter function was used in the graph to make multiple identical values more visible.

was $0.83(P<0.01)$. However, we attained the highest correlation with counts of locomotor play when using counts of peaks of $\geq+1.6 \mathrm{~g}$ and $\leq-3.0 \mathrm{~g}$ (Pearson $\mathrm{r}$ $=0.91, P>0.01 ;$ Figure 1$)$. The respective scatter plot (Figure 1) illustrated a strong linear relationship of both measurements, but an unequal rate of increase of counts of peaks with counts of play was noticeable. The Bland-Altman plot (Figure 2) further emphasized the uneven distribution across the range of locomotor play; higher counts of locomotor play events were increasingly underestimated by the peak acceleration method, demonstrating that the number of play events and the number of accelerometer peaks did not directly correspond (i.e., they were not on the same scale). The mean deviation of peak measurements from observed play events was $-1.90 \pm 4.42$.

Alternatively, when recording locomotor play with one-zero sampling, calves performed play in 2.7 periods per observation $(\mathrm{SD}=3.5$; range $=0-16)$. From the accelerometer data, we estimated the number of play periods using the classifier method with the outcome displayed as a contingency table (Table 3). The classifier method overestimated the number of play periods, achieving a precision (proportion of correctly classified periods) of 0.95 , a sensitivity (proportion of correctly classified true positives) of 0.79 , and a specificity (proportion of correctly classified true negatives) of 0.96 . Counts of play periods identified by the classifier method were highly correlated with counts of observed play periods recorded from video (Pearson $\mathrm{r}=0.87 ; P<$ 0.01; Figure 3). The scatter plot (Figure 3) illustrated a strong linear relationship of both measurements but
Table 3. Contingency table with number of periods identified with the classifier method as play (event of locomotor play occurring in this period) and no play (no event of locomotor play occurring in this period)

\begin{tabular}{lccr}
\hline & \multicolumn{3}{c}{ Predicted behavior (classifier) } \\
\cline { 2 - 4 } $\begin{array}{l}\text { Observed behavior } \\
\text { video) }\end{array}$ & No play & Play & Sum \\
\hline No play & 4,591 & 202 & 4,793 \\
Play & 27 & 102 & 129 \\
Sum & 4,618 & 304 & 4,922 \\
\hline
\end{tabular}

indicated an intercept and concomitant overestimation of play periods by the classifier method. The number of accelerometer-identified play periods surpassed the number recorded visually by $3.65 \pm 2.42$ periods; nonetheless, the Bland-Altman plot (Figure 4) showed an evenly distributed deviation of the 2 measurements across the range of counts of play periods.

\section{DISCUSSION}

With this study, we aimed at providing an approach to automatically record locomotor play of calves in their home pen and for long durations using acceleration measurements. In previous studies, accelerometers have been validly used to record durations of lying and standing in calves (Bonk et al., 2013; Swartz et al., 2016). Similarly, in the current study, we were able to easily distinguish between lying and standing on the

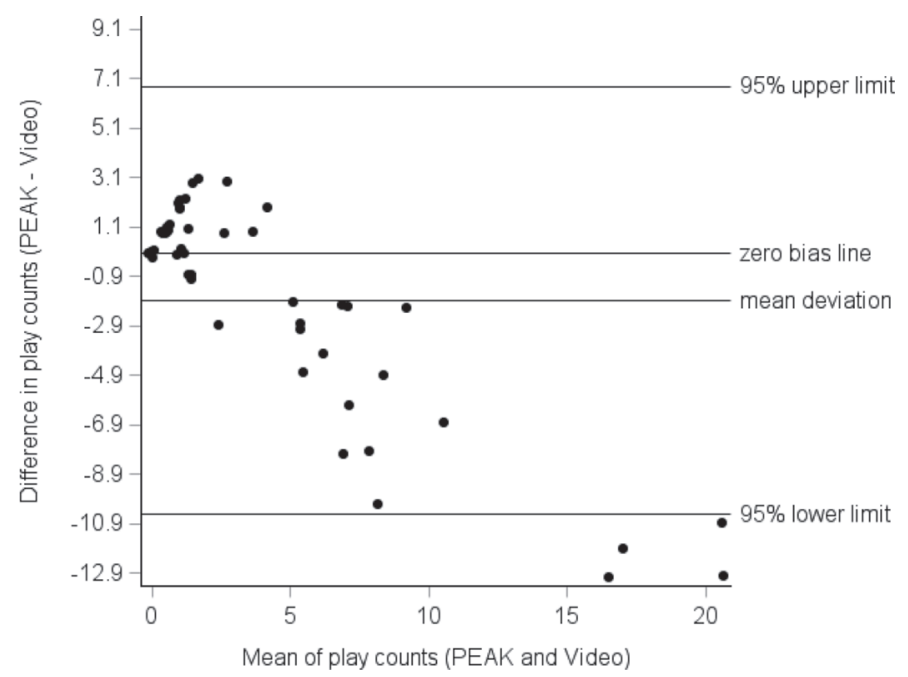

Figure 2. Bland-Altman plot of the difference in the assessment of locomotor play recorded with accelerometers and video observation compared with the mean of both assessments (PEAK = peak acceleration method; $\mathrm{n}=48$ calves). Confidence intervals were estimated at 6.8 at the $95 \%$ upper limit and -10.6 at the $95 \%$ lower limit. Jitter function was used in the graph to make multiple identical values more visible. 


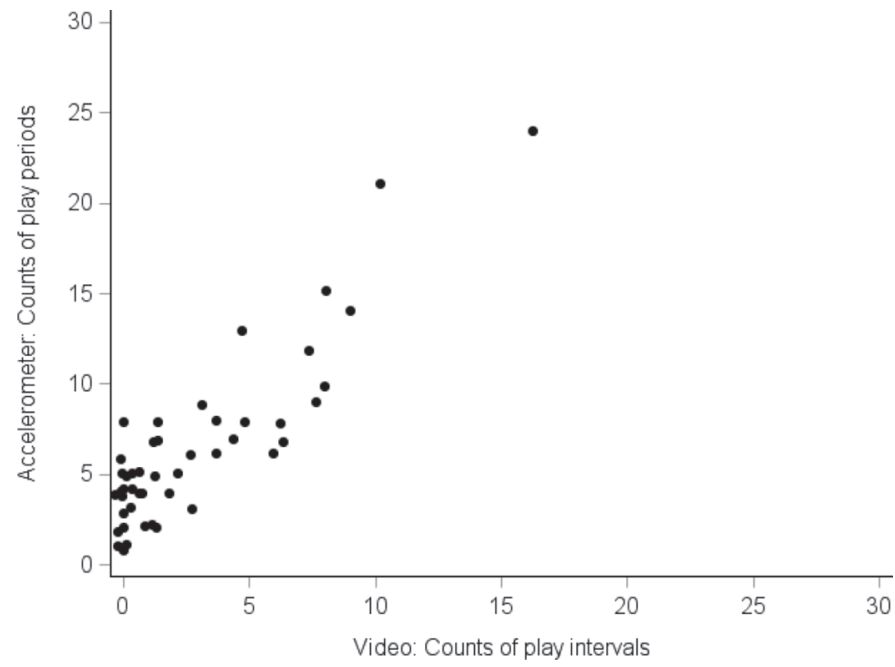

Figure 3. Relationship between counts of periods with locomotor play identified with accelerometers (classifier method) and counts of sample intervals with locomotor play observed from video $(\mathrm{n}=48$ calves). Jitter function was used in the graph to make multiple identical values more visible.

vertical axis, with values of lying fluctuating around $0 \mathrm{~g}$ and values of standing around $-1 \mathrm{~g}$, depending on the position of the hind leg. Therefore with $-1 g$ as the center of fluctuation, measuring play with peaks of $\geq+1.6 \mathrm{~g}$ and $\leq-3.0 \mathrm{~g}$ is sensible. We reason that peaks had not reached $+3.0 \mathrm{~g}$, as reported by Luu et al. (2013), because the smaller dimensions of the home pens compared with a large arena did not permit calves

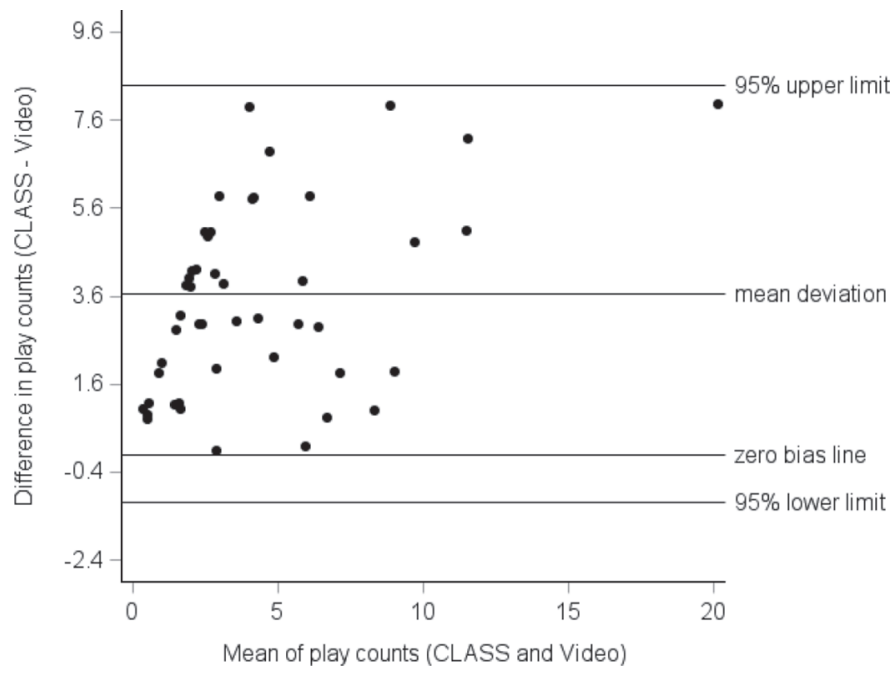

Figure 4. Bland-Altman plot of the difference in the assessment of locomotor play periods identified with accelerometers and locomotor play intervals from video observation compared with the mean of both assessments (CLASS $=$ classifier method; $\mathrm{n}=48$ calves). Confidence intervals were estimated at 8.4 at the $95 \%$ upper limit and -1.1 at the $95 \%$ lower limit. Jitter function was used in the graph to make multiple identical values more visible. to consistently reach accelerations of a similarly high level. Thus, small spaces can restrict the magnitude of movement and fragment the occurrence of play (Jensen et al., 1998). Nevertheless, we cannot draw conclusions on any space allowance between our home pen and the arena of Luu et al. (2013) because this was not part of our investigation. Moreover, locomotor play consists of rapid motions of the hind legs for short durations and is often nested within short time intervals. Therefore, recordings at $1 \mathrm{~Hz}$ and on one axis may be too infrequent to accurately capture locomotor play events in the home pen, resulting in the unequal increase and accretive underestimation of higher frequencies of play events of the peak acceleration method, as visualized in the scatter plot and Bland-Altman plot. Nevertheless, the high correlation of peak accelerations and observed play events indicated a strong link between the 2 recording methods. Thus, although the peak acceleration method cannot record the duration of play in absolute terms, it can produce an approximate estimation of play levels and allows comparison of relative differences between calves in standard housing conditions.

In the classifier method, we used accelerometer data to simulate the one-zero observational method by merging the recordings to 10 -s periods, ensuring the use of repeated measures and circumventing the need to count individual peaks above or below a certain threshold. This allowed us to view acceleration values in context, integrated with the values preceding and following them. We derived classifiers from combined values; for example, the mean of the 2 highest values or variance to mathematically describe the 10 acceleration measures per period and highlight the differences between play and no play. Thus, we classified brief time spans according to the presence or absence of locomotor play within these $10 \mathrm{~s}$. The use of original individual acceleration values; for example, the minimum or maximum value, would have resulted in lower sensitivity to correctly identify play periods. Such an approach has been previously successfully implemented in accelerometer validation regarding sheep gait, describing periods with relative frequencies of integers; for example, the number of high-frequency acceleration readings between $-4 g$ and $-3 g$ per period divided by all readings of the period (Radeski and Ilieski, 2017). Other studies described periods using movement metrics; for example, mean, variance, and inverse coefficient of variation (Watanabe et al., 2008) or signal magnitude area, average intensity, and average entropy (Barwick et al., 2018). However, in these studies, acceleration was recorded at a higher rate. Recording at a higher rate would have allowed us to classify shorter periods. For example, Radeski and Ilieski (2017) recorded at $33 \mathrm{~Hz}$ and classified periods of $3 \mathrm{~s}$. 
The classifier method correctly discriminated $79 \%$ of periods with an occurrence of locomotor play, but at the same time overestimated play by approximately $200 \%$ (out of 304 play periods identified by the classifier method, 102 periods were true positives and 202 periods were false positives). Similarly, other accelerometer models consistently overestimated locomotor behavior; for example, Swartz et al. (2016) overestimated stepping by $18 \%$ and Trénel et al. (2009) consistently overestimated moving activity with a ratio of probability of correct negatives to correct positives of 7.57 (negative predictive value $=0.98$, positive predictive value $=0.13)$. Thus, although the number of classified play periods is strongly associated with counts of observed play intervals, the classifier method overestimates locomotor play in absolute terms overall and produces an intercept by adding 3.7 play periods to each observation. However, the Bland-Altman plot shows a consistent and evenly distributed deviation across the range of number of play intervals observed without indication of a directed effect. Hence, although the classifier method cannot accurately measure locomotor play, it can be used as a proxy. After factoring in the consistent overestimation, it assesses the number of play periods close to the scale of one-zero sampling and thus allows comparison of absolute differences between individuals. With these results, we offer a feasible approach to assess spontaneous locomotor play in home pens of calves using an affordable and commercially available accelerometer model for durations of many hours or perhaps even days. Nevertheless, these results may only be valid for the housing conditions investigated and further studies are needed to validate this approach under, for example, different space allowances. A prerequisite to classify periods with discriminant analysis is to use shorter subsets of behavior recordings as a training data set. In the current study, only active periods of animals were included in the analysis. To apply the classifier method to the full data set, it is necessary to either preselect only active periods or to include lying bouts in the training data set. It is feasible to train the discriminant function with the selected classifiers and thereafter to apply it to the entire recordings of acceleration.

We must stress that our proposed approach with recording at a frequency of $1 \mathrm{~Hz}$ can only be used as an approximate estimation of locomotor play. A higher level of accuracy could be achieved by increasing the rate of recording. Measuring acceleration at the highest rate $(33 \mathrm{~Hz})$ allowed de Passillé et al. (2010) to measure the inter-step interval and accurately distinguish between different gait patterns. Radeski and Ilieski (2017) were able to achieve high accuracy in classifying 3 -s periods of walking, trotting, and galloping in sheep with discriminant analysis, when recorded at a rate of $33 \mathrm{~Hz}$. In the current study, the recording rate was limited by its data storage capacity; however, Le Roux et al. (2018) achieved a 469-fold reduction in memory requirement when classifying lying, standing, and walking on the accelerometer rather than storing raw data. Thus, the proposed approach is easily applicable and inexpensive with the available resources; however, numerous options exists to improve the accuracy of recording through technical advancements.

\section{CONCLUSIONS}

Using the peak acceleration method, the acceleration of calves' hind legs measured at a rate of $1 \mathrm{~Hz}$ can be used to obtain an approximate estimation of inter-individual differences in the occurrence of locomotor play events. Quadratic discriminant analysis can replace observational one-zero sampling when based on indirect movement metrics obtained from 10-s periods of raw accelerometer data. This alternative method may be more accurate in quantifying the inter-individual differences in locomotor play of dairy calves in their home pens because it reveals less biased estimates across different levels of play. If the accurate measurement of absolute levels of behavior is the ultimate aim of automatic recording, a sensor with higher memory capacity must be found.

\section{ACKNOWLEDGMENTS}

We are grateful to the farm staff at the Netluky Research Station for the care of calves and cooperation with the research team. This study was funded by the Austrian Academy of Sciences (Vienna, Austria) and by the grant MZE-RO0718 from the Czech Ministry of Agriculture (Prague, Czech Republic). V. Größbacher received a DOC Fellowship from the doctoral program of the Austrian Academy of Sciences.

\section{REFERENCES}

Altman, D. G., and J. M. Bland. 1983. Measurement in medicine: The analysis of method comparison studies. Statistician 32:307-317.

Barwick, J., D. W. Lamb, R. Dobos, M. Welch, and M. Trotter. 2018. Categorising sheep activity using a tri-axial accelerometer. Comput. Electron. Agric. 145:289-297. https://doi.org/10.1016/j .compag.2018.01.007.

Bonk, S., O. Burfeind, V. S. Suthar, and W. Heuwieser. 2013. Technical note: Evaluation of data loggers for measuring lying behavior in dairy calves. J. Dairy Sci. 96:3265-3271. https://doi.org/10 .3168/jds.2012-6003.

de Passillé, A. M., M. B. Jensen, N. Chapinal, and J. Rushen. 2010. Technical note: Use of accelerometers to describe gait patterns in dairy calves. J. Dairy Sci. 93:3287-3293. https://doi.org/10.3168/ jds.2009-2758.

Fraser, D., and I. J. H. Duncan. 1998. 'Pleasures', 'pains' and animal welfare: Toward a natural history of affect. Anim. Welf. 7:383-396. 
James, G., D. Witten, T. Hastie, and R. Tibshirani. 2015. An Introduction to Statistical Learning with Applications in R. Springer Science+Business Media, New York, NY. https://doi.org/10.1007/ 978-1-4614-7138-7.

Jensen, M. B., L. R. Duve, and D. M. Weary. 2015. Pair housing and enhanced milk allowance increase play behavior and improve performance in dairy calves. J. Dairy Sci. 98:2568-2575. https://doi .org $/ 10.3168 /$ jds.2014-8272.

Jensen, M. B., and R. Kyhn. 2000. Play behaviour in group-housed dairy calves, the effect of space allowance. Appl. Anim. Behav. Sci. 67:35-46. https://doi.org/10.1016/S0168-1591(99)00113-6.

Jensen, M. B., K. S. Vestergaard, and C. C. Krohn. 1998. Play behaviour in dairy calves kept in pens: the effect of social contact and space allowance. Appl. Anim. Behav. Sci. 56:97-108. https://doi .org/10.1016/S0168-1591(97)00106-8.

Krachun, C., J. Rushen, and A. M. de Passillé. 2010. Play behaviour in dairy calves is reduced by weaning and by a low energy intake. Appl. Anim. Behav. Sci. 122:71-76. https://doi.org/10.1016/ j.applanim.2009.12.002.

Kuhlenkasper, T., and A. Handl. 2017. Diskriminanzanalyse. Pages 363-413 in Multivariate Analysemethoden. Theorie und Praxis mit R. 3rd ed. Springer Spektrum, Berlin, Heidelberg. https://doi .org/10.1007/978-3-662-54754-0_12.

Le Roux, S. P., R. Wolhuter, N. Stevens, and T. Niesler. 2018. Reduced energy and memory requirements by on-board behavior classification for animal-borne sensor applications. IEEE Sens. J. 18:4261-4268. https://doi.org/10.1109/jsen.2018.2816965.

Luu, J., J. F. Johnsen, A. M. d. Passillé, and J. Rushen. 2013. Which measures of acceleration best estimate the duration of locomotor play by dairy calves? Appl. Anim. Behav. Sci. 148:21-27. https:// doi.org/10.1016/j.applanim.2013.07.004.

Miguel-Pacheco, G. G., A. Vaughan, A. M. de Passille, and J. Rushen. 2015. Relationship between locomotor play of dairy calves and their weight gains and energy intakes around weaning. Animal 9:1038-1044. https://doi.org/10.1017/S1751731115000063.

Mintline, E. M., M. Stewart, A. R. Rogers, N. R. Cox, G. A. Verkerk, J. M. Stookey, J. R. Webster, and C. B. Tucker. 2013. Play behavior as an indicator of animal welfare: Disbudding in dairy calves. Appl. Anim. Behav. Sci. 144:22-30. https://doi.org/10.1016/j .applanim.2012.12.008.

Overvest, M. A., R. E. Crossley, E. K. Miller-Cushon, and T. J. DeVries. 2018. Social housing influences the behavior and feed intake of dairy calves during weaning. J. Dairy Sci. 101:8123-8134. https://doi.org/10.3168/jds.2018-14465.

Radeski, M., and V. Ilieski. 2017. Gait and posture discrimination in sheep using a tri-axial accelerometer. Animal 11:1249-1257. https: //doi.org/10.1017/S175173111600255X.

Roland, L., V. Schweinzer, P. Kanz, G. Sattlecker, F. Kickinger, L. Lidauer, A. Berger, W. Auer, J. Mayer, V. Sturm, D. Efrosinin, S. Breitenberger, M. Drillich, and M. Iwersen. 2018. Technical note:
Evaluation of a triaxial accelerometer for monitoring selected behaviors in dairy calves. J. Dairy Sci. 101:10421-10427. https://doi .org/10.3168/jds.2018-14720.

Rushen, J., and A. M. de Passillé. 2012. Automated measurement of acceleration can detect effects of age, dehorning and weaning on locomotor play of calves. Appl. Anim. Behav. Sci. 139:169-174. https://doi.org/10.1016/j.applanim.2012.04.011.

SAS Institute. 2012. User's Guide: Statistics, Version 9.4 edition. SAS Institute, Inc., Cary, NC.

Sutherland, M. A., J. Larive, V. Cave, and G. Zobel. 2018a. Behavioural and physiological responses to clove oil injected under the horn bud of calves. Appl. Anim. Behav. Sci. 204:29-36. https://doi .org/10.1016/j.applanim.2018.03.004.

Sutherland, M. A., G. L. Lowe, F. J. Huddart, J. R. Waas, and M. Stewart. 2018b. Measurement of dairy calf behavior prior to onset of clinical disease and in response to disbudding using automated calf feeders and accelerometers. J. Dairy Sci. 101:8208-8216. https: //doi.org/10.3168/jds.2017-14207.

Swartz, T. H., A. N. Findlay, and C. S. Petersson-Wolfe. 2017. Short communication: Automated detection of behavioral changes from respiratory disease in pre-weaned calves. J. Dairy Sci. 100:92739278. https://doi.org/10.3168/jds.2016-12280.

Swartz, T. H., M. L. McGilliard, and C. S. Petersson-Wolfe. 2016. Technical note: The use of an accelerometer for measuring step activity and lying behaviors in dairy calves. J. Dairy Sci. 99:91099113. https://doi.org/10.3168/jds.2016-11297.

Trénel, P., M. B. Jensen, E. L. Decker, and F. Skjøth. 2009. Technical note: Quantifying and characterizing behavior in dairy calves using the IceTag automatic recording device. J. Dairy Sci. 92:3397-3401. https://doi.org/10.3168/jds.2009-2040.

Valníčková, B., I. Stěhulová, R. Šárová, and M. Špinka. 2015. The effect of age at separation from the dam and presence of social companions on play behavior and weight gain in dairy calves. J. Dairy Sci. 98:5545-5556. https://doi.org/10.3168/jds.2014-9109.

Watanabe, N., S. Sakanoue, K. Kawamura, and T. Kozakai. 2008. Development of an automatic classification system for eating, ruminating and resting behavior of cattle using an accelerometer. Grassl. Sci. 54:231-237. https://doi.org/10.1111/j.1744-697X.2008 $.00126 . x$.

Wathan, J., A. M. Burrows, B. M. Waller, and K. McComb. 2015. EquiFACS: The Equine Facial Action Coding System. PLoS One 10:e0137318. https://doi.org/10.1371/journal.pone.0137818.

\section{ORCIDS}

V. Größbacher (® https://orcid.org/0000-0001-8607-9810

M. Špinka ๑ https://orcid.org/0000-0002-2506-9552

C. Winckler (1) https://orcid.org/0000-0002-2221-0186 